\title{
Molecular identification of brood-parasitic females reveals an opportunistic reproductive tactic in ruddy ducks
}

\author{
LETITIA M. REICHART,* SOFIA ANDERHOLM,†VIOLETA MUÑOZ-FUENTES $\ddagger \S$ and \\ MICHAEL S. WEBSTER,* \\ *School of Biological Sciences, Washington State University, P. O. Box 644236, Pullman, WA 99164-4236, USA, †Department of \\ Zoology, University of Gothenburg, Box 463, SE-405 30, Goteborg, Sweden, ¥Department of Evolutionary Biology, Uppsala \\ University, Norbyvägen 18D, SE-752 36 Uppsala, Sweden, §Estación Biológica de Doñana- CSIC, Avda. Americo Vespucio s/n, \\ 41092 Sevilla, Spain
}

\begin{abstract}
In many taxa, females lay eggs in the nests of other conspecifics. To determine the conditions under which conspecific brood parasitism develops, it is necessary to identify parasitic offspring and the females who produce them; however, for most systems parasitism can be difficult to observe and most genetic approaches have relatively low resolving power. In this study, we used protein fingerprinting from egg albumen and 10 microsatellite loci to genetically match parasitic ducklings to their mothers in a population of ruddy ducks (Oxyura jamaicensis). We found that $67 \%$ of nests contained parasitic offspring, and we successfully identified their mothers in $61 \%$ of the cases. Of the parasitic females identified, $77 \%$ also had nests of their own (i.e. a dual tactic, where females both nest and lay parasitically), and we found no evidence that parasitic females pursued a specialist (parasitism only) tactic. We also found that parasitic egg laying was not influenced by nest loss, predation or female condition. Thus, in contrast to most waterfowl studied to date, female ruddy ducks appear to lay parasitic eggs whenever the opportunity arises.
\end{abstract}

Keywords: alternative reproductive tactics, brood parasitism, intra-specific nest parasitism, parentage analysis, protein fingerprinting, ruddy duck

\section{Introduction}

Conspecific brood parasitism (CBP) is a reproductive tactic in which a female lays some or all of her eggs in the nests of other conspecific females. This behaviour is intriguing because females who lay parasitically do not provide parental care to their parasitic offspring; instead, host females incur the parental care costs of raising them. Although this behaviour occurs in over 200 species of birds (Yom-Tov 1980, 2001), many fishes and amphibians (Harris et al. 1995; Wisenden 1999) and various species of insects (Brockman 1993; Tallamy

Correspondence: Letitia M. Reichart, Biology Department, University of Nebraska Kearney, 905 W. 25th Street, Kearney, NE 68849, USA. E-mail: reichartlm@unk.edu
2005), the factors that favour parasitism remain unclear for most species.

In birds and some other taxa, CBP generally appears to be a conditional reproductive tactic, such that any female may lay parasitic eggs in response to extrinsic ecological (e.g., nest site availability) and/or intrinsic (e.g., a female's physiological condition) factors that limit reproductive fitness (Sorenson 1991; Sayler 1992; Lyon \& Eadie 2008). According to the general framework developed by Sorenson (1991), each female engages in one of four reproductive behaviours as part of a conditional tactic: nonbreeding, parasitic egg laying, nesting and nesting plus parasitic egg laying (i.e. a dual tactic). Under this general framework, both nesting and non-nesting females can lay parasitic eggs. However, each context (i.e. nesting and non-nesting) yields 
separate hypotheses to explain the adaptive significance of CBP within a population given a variety of fitness costs and benefits (Lyon \& Eadie 2008).

There are several hypotheses for the adaptive significance of parasitism by non-nesting females. First, parasitism by non-nesting females may be in response to nest site limitation. This hypothesis predicts that if nest sites are limited, females will lay eggs parasitically rather than forgo breeding. Non-nesting females benefit through parasitic egg laying via current fecundity and avoid the cost of acquiring a nest site (i.e. a cost in adult survival). Although this hypothesis may be particularly important in cavity-nesting species (e.g., Andersson \& Eriksson 1982; Eadie 1989, 1991; Semel \& Sherman 2001), it seems less likely to hold for overwater-nesting species where nest sites do not appear to be limited.

Second, parasitism by non-nesting females may occur in response to intrinsic limitations of the female. This hypothesis predicts that nesting (i.e. nest building, nest defence and incubation) is energetically expensive, and that parasites are able to reach the energetic threshold necessary for egg production but not for nesting behaviour (i.e. parasitic females are inexperienced and/or in poor physiological condition, Sorenson 1991; Sayler 1992). Here, non-nesting females parasitize as a low cost alternative to nesting, gaining some reproductive success.

Third, parasitism by non-nesting females may occur as a specialist tactic, maintained by balancing selection, where some females obtain maximum fecundity via egg production and bypass costs associated with nesting behaviour. This hypothesis predicts that nesting and non-nesting females laying parasitically are equally fecund reproductive tactics; however, to date there is no evidence of lifelong specialist parasites in avian species (Lyon \& Eadie 2008).

Finally, females who engage in CBP may be nesting females, rather than non-nesting females, and we discuss two hypotheses that might explain CBP in this context. First, a nesting female could use CBP as a conditional reproductive tactic if she loses her nest (e.g., due to nest predation; Feare 1991; Jackson 1993) but does not have the time or energy reserves to re-nest. Under these conditions, a female engages in post-predation parasitism rather than forgoing breeding for the remainder of the season (Haramis et al. 1983).

Alternatively, nesting females in excellent condition may be able to nest and also lay additional eggs parasitically (Sorenson 1991) because they are limited by clutch size in their own nest (e.g., via incubation constraints). This hypothesis predicts that CBP will increase the fitness of nesting females by increasing total reproductive output (Trivers 1972), particularly if laying parasitic egg(s) yields higher fitness than would an additional egg laid in the female's own nest (Lyon 1998).

In addition to the above hypotheses, several extrinsic factors may affect the frequency in which CBP occurs. For example, opportunities to lay parasitic eggs could be affected by nest density (Brown 1984; Eadie \& Fryxell 1992; Sayler 1992; Møller 1998) and/or nesting synchrony among conspecific females (Lyon 1993a,b; McRae \& Burke 1996). The influence of these factors on the propensity of females to lay parasitic eggs has been difficult to assess because few studies have assigned parasitic eggs to specific females.

To distinguish among these hypotheses and to evaluate the influence of extrinsic factors on the frequency of CBP, some previous studies have identified parasitic offspring using nongenetic techniques (e.g., Yom-Tov 1980; Pinxten et al. 1991; Jackson 1992; Lyon 1993a,b; Lahti \& Lahti 2002), whereas others have used molecular methods to identify parasitic young /eggs by comparing the genotypes of young in a brood with that of the attending female (reviewed by Arnold \& Owens 2002). Although these methods have been useful in identifying parasitic offspring, it has proven much more challenging to identify the parasitic females that produce them (but see Jaatinen et al. 2009). To identify parasitic females, some previous studies relied on behavioural observations (Eadie 1989; Sorenson 1991, 1993) or variation in egg colour (Jackson 1992; Lyon 1993a,b), but these techniques have limited applicability. Molecular techniques offer an alternative approach, potentially applicable to a wide variety of species. However, molecular identification of parasitic females is challenging because typically neither parent is known for the parasitic offspring and a number of females in the population could possess alleles compatible with a given egg. This problem is particularly acute if markers show low levels of polymorphism, if a large number of females are candidate parasites, and/or if some females in the population are closely related (Richardson et al. 2001).

In this study, we examine brood parasitism in the ruddy duck (Oxyura jamaicensis), a species in which CBP has been demonstrated previously (Siegfried 1976; Joyner 1983). Ruddy duck eggs appear to be unusually costly to produce (see Materials and methods), and over-water nesting sites do not appear limited (i.e. abundant over-water nesting habitat is available in our population). This makes the ruddy duck a useful model species for investigating CBP: the minimum energy threshold for laying eggs is probably high, whereas the additional energy necessary to nest should be minimal (e.g., rate of invertebrate consumption increases until onset of incubation, then remains constant throughout 


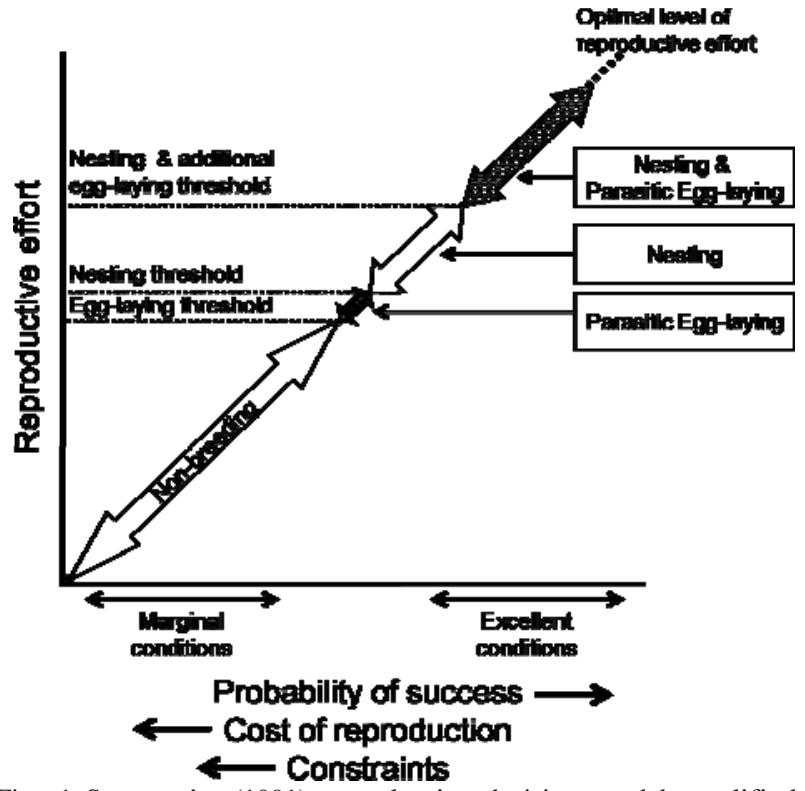

Fig. 1 Sorenson's (1991) reproductive decision model modified for female ruddy ducks, where optimal reproductive effort can vary along the $45^{\circ}$ line (hashed) depending on costs and benefits of reproduction each year. Reproductive options (i.e. nonbreeding, parasitism only, nesting only, nesting plus laying parasitic eggs) available for females arriving on the breeding grounds vary as individuals reach the energetic thresholds required for each behaviour. For female ruddy ducks, egg laying is unusually costly and the energetic thresholds required for egg laying and independent nesting behaviour are probably higher than in other waterfowl species. In ruddy ducks, the threshold for egg laying is almost equal to the threshold for nesting, and accordingly parasitic egg laying without independent nesting should be relatively rare. Instead, females unable to reach the high energetic threshold for egg laying (and independent nesting) probably will be nonbreeders that forego breeding altogether.

incubation, Alisauskas \& Ankney 1994). Hence, the thresholds for egg laying and nesting should be nearly concordant, and we expect few if any female ruddy ducks to produce parasitic eggs and not nest (Fig. 1). Accordingly, we predicted that parasites would be nesting females in good condition, pursuing a dual reproductive tactic. We further predicted that ecological conditions, such as high nest density and/or synchrony, would facilitate parasitism. To test these predictions, we used two molecular genetic markers, egg albumen protein fingerprinting (a maternal marker) and autosomal nuclear microsatellite loci, to identify both parasitic offspring and their biological mothers. Because our molecular approaches allowed us to determine the females who produced the parasitic eggs, we could examine individual reproductive tactics of female ruddy ducks, and test hypotheses that might explain why a female lays parasitic eggs.
Materials and methods

\section{Study species}

Egg laying appears more costly for female ruddy ducks than for most other waterfowl due to rapid use of nutrient reserves (Alisauskas \& Ankney 1994). Ruddy ducks lay a clutch of 6-8 eggs (Joyner 1975), usually laying one egg per day, each weighing approximately $14 \%$ of a female's body weight (Gray 1980; Alisauskas \& Ankney 1992, 1994). Maximum daily cost of egg production as well as resource requirements during egg laying and incubation are high (Gray 1980; Carbonell 1983; Tome 1987; Alisauskas \& Ankney 1994). Ruddy ducks are single brooded, and few females re-nest after nest loss (Sommerville 1985; Tome 1987), probably due to the high nutritional demand of egg formation and lateness of nest initiation (Brua 2001).

Ruddy duck offspring are highly precocial and able to forage on their own immediately after hatching (Sommerville 1985). Adult females provide minimal parental care, mainly in the form of predator vigilance, and stay with a brood from 28 to 42 days after hatching (Joyner 1975; Gray 1980). Females do not feed their offspring (Joyner 1975); however, offspring survival is high (Bellrose 1980), and ducklings from larger eggs have a higher probability of survival (Pelayo \& Clark 2002, 2003).

\section{Field data and sample collection}

We conducted fieldwork during the ruddy duck-breeding season (mid-May to early August) each year from 2003 to 2005 in the prairie pothole region of Minnedosa, Manitoba, Canada $\left(50^{\circ} 10 \mathrm{cN}, 99^{\circ} 47 \mathrm{cW}\right)$. Female ruddy ducks build nests over water in emergent vegetation of wetland margins. The area is characterized by many permanent and ephemeral wetlands (Pelayo \& Clark 2003) consequently, nesting habitat is abundant.

We trapped adult ruddy ducks prior to nesting using floating mist nets (after Breault \& Cheng 1989). Once nesting began, we also trapped adult females during late incubation (eggs approximately 18-20 days) using drop-door nest traps (Weller 1957). At the time of capture, we weighed each adult to the nearest gram using a Pesola spring scale, collected morphological measures (tarsus length, wing chord, bill length and width) and collected a blood sample (approximately $1001 \mathrm{~L}$ stored in $1 \mathrm{~mL}$ of lysis buffer, White \& Densmore 1992) from the tarsus vein. We marked females using temporary, modified nasal discs (Pelayo \& Clark 2000) and federal leg bands. We trapped 112 adult females, but could not trap all females present on the study site. 
We searched for nests in emergent vegetation around wetlands, and marked each nest location using a numbered stake placed on land 5-15 m away. We used an egg floatation method developed for ruddy ducks (Brua \& Machin 2000) to measure embryonic development. We estimated nest initiation date by back-dating from the stage of embryonic development. Nests were rechecked every 7 days to evaluate developmental stage and nest fate.

To reduce loss of samples to predators and because precocial young leave the nest very soon after hatching, we trapped females during late incubation (see above) and replaced their clutches with an identical number of nonviable chicken eggs (after Pelayo \& Clark 2003). Nest abandonment was rare (L. M. Reichart, pers. obs.), because females were trapped during late incubation, before eggs hatched. Removed ruddy duck eggs were artificially incubated in air-circulating cabinet incubators at $37^{\circ} \mathrm{C}, 67-70 \%$ humidity. When incubated eggs hatched, we kept ducklings in brooders until dry (approximately 3-4 h), banded each duckling with a federal duckling band (wood duck size B, prepared with a clay mixture of $50 \%$ Chavant DaVinci soft and $50 \%$ Roma Plastilina \#1; Blums et al. 1999), weighed the duckling to the nearest $0.01 \mathrm{~g}$ and collected a blood sample as previously described. Ducklings were then returned to nests of origin; nesting females incubated chicken eggs for $<5$ days before their ducklings were returned.

We collected blood samples from 112 females and 516 ducklings from 80 nests for genetic analysis. We also collected egg albumen from 126 eggs from 20 nests found during laying or early incubation (13 days). To collect albumen, we punctured a small hole through the egg shell, removed approximately 200-300 IL of egg albumen with a syringe (Andersson \& Åhlund 2001), and then sealed the hole with Aron Alpha Instant Krazy Glue ${ }^{\circledR}$ (ethyl cyanoacrylate). Albumen samples were immediately stored on ice, and placed at $) 20^{\circ} \mathrm{C}$ until protein fingerprint analysis. Eggs were then placed back into the nest and developed normally, with no effect on hatching success (L. M. Reichart, pers. obs.).

\section{Protein fingerprinting}

Protein fingerprinting uses isoelectric focusing to separate proteins across an electric field applied over a fixed $\mathrm{pH}$ gradient in precast gels. The proteins are visualized as narrow bands on a gel, representing their isoelectric points (Righetti 1990). Egg albumen is of maternal origin, and exclusively represents the genotype of the female that laid the egg rather than that of the developing embryo. Andersson \& Åhlund (2001) demonstrated that protein bands are both reproducible and genetically polymorphic across females, providing resolution sufficient to detect parasitic eggs and sometimes the females who laid them.

To resolve a sufficient number of protein variants, albumen samples were run on four precast polyacrylamide gel types: three dehydrated (Immobiline DryPlates; GE Healthcare) and one hydrated (Proteios, Netherlands). All gels were run on an Amersham Biosciences Multiphor II System with electrophoresis power supply EPS 3501 and a cooling temperature of $10{ }^{\circ} \mathrm{C}$. Dehydrated gels were stored at ) $20^{\circ} \mathrm{C}$ and rehydrated in a solution containing reagents to maximize number and sharpness of the bands according to Andersson \& Åhlund (2001). The $\mathrm{pH}$ ranges used were 47 (type C) and 4.5-5.4 (type B + D) (Andersson \& Àhlund 2001). Gels were loaded with 5 IL crude albumen and run for 6-12 h at $3000 \mathrm{~V}, 1 \mathrm{~mA}$ and $3 \mathrm{~W}$. Hydrated gels (Proteios, $\mathrm{pH}$ 3-10) were stored at $4{ }^{\circ} \mathrm{C}$ and run with diluted albumen samples [one part albumen in seven parts of a $10 \%(\mathrm{v} / \mathrm{v})$ glycerol, $1.5 \%(\mathrm{v} / \mathrm{v})$ carrier ampholyte (Servalyt, $\mathrm{pH}$ 3-10) de-ionized water solution]. Gels were loaded with $7 \mathrm{IL}$ of diluted albumen on a 48-well applicator strip after a prefocusing step of 150 Volt Hours (VH) at maximum $750 \mathrm{~V}$, and followed by $100 \mathrm{VH}$ at $200 \mathrm{~V}, 200 \mathrm{VH}$ at $500 \mathrm{~V}$ and $5000 \mathrm{VH}$ at $3000 \mathrm{~V}$ (all at max $25 \mathrm{~mA}, 10 \mathrm{~W}$ ). The electrode wicks were soaked with an anode and cathode electrode solution (Serva, no. 42984 and 42986).

After electrophoresis, Proteios gels were fixed in a $20 \%(\mathrm{w} / \mathrm{v})$ Trichloroacetic acid solution for $30 \mathrm{~min}$ (15 min still, $15 \mathrm{~min}$ gently shaking), then stained for $30 \mathrm{~min}$ in a $10 \%(\mathrm{w} / \mathrm{v})$ VWR Coomassie 250-R/destaining solution (one part acetic acid, four parts ethanol and five parts de-ionized water). After staining, gels were washed several times in destaining solution until background was clear. Before drying, gels were wiped with a de-ionized water-soaked soft tissue to remove excess dye, and washed $3-5 \mathrm{~min}$ in de-ionized water. The gels were air dried for approximately $24 \mathrm{~h}$ before being read.

We scored all identifiable bands as present or absent for each individual. The most common albumen pattern among eggs in a nest was assumed to represent the nesting (host) female (after Andersson \& Åhlund 2001). Eggs with differing band patterns on at least one gel type were scored as parasitic and comparison of band patterns allowed us to determine the number of parasitic females contributing eggs to a nest.

\section{DNA microsatellite methods}

We used variation at 10 microsatellite loci to identify parasitic ducklings and match them to adult females in 
Table 1 Locus specific PCR conditions and variability of ten microsatellite loci for adult ruddy ducks sampled 2003-2005

\begin{tabular}{|c|c|c|c|c|c|c|c|c|}
\hline \multirow[b]{2}{*}{ Locus } & \multirow[b]{2}{*}{$\mathrm{n}^{*}$} & \multirow[b]{2}{*}{$\begin{array}{l}\text { No. of } \\
\text { alleles }\end{array}$} & \multirow[b]{2}{*}{$\begin{array}{l}\text { Annealing } \\
\text { temperature } \\
\left({ }^{\circ} \mathrm{C}\right)\end{array}$} & \multirow[b]{2}{*}{$\begin{array}{l}\mathrm{MgCl}_{2} \\
\text { concentration } \\
(\mathrm{mM})\end{array}$} & \multicolumn{2}{|c|}{ Heterozygosity } & \multirow[b]{2}{*}{$\begin{array}{l}\text { Frequency } \\
\text { of null allele }\end{array}$} & \multirow[b]{2}{*}{$\mathrm{P}_{\text {exclusion }} \dagger$} \\
\hline & & & & & $\begin{array}{l}\text { Expected } \\
\left(\mathrm{H}_{\mathrm{E}}\right)\end{array}$ & $\begin{array}{l}\text { Observed } \\
\left(\mathrm{H}_{\mathrm{O}}\right)\end{array}$ & & \\
\hline Oxy3 & 158 & 4 & 62 & 2.00 & 0.115 & 0.108 & 0.026 & 0.007 \\
\hline Oxy6 & 161 & 3 & 62 & 2.00 & 0.457 & 0.447 & 0.012 & 0.104 \\
\hline Oxy10 & 161 & 11 & 62 & 2.00 & 0.816 & 0.783 & 0.021 & 0.463 \\
\hline Oxy13 & 160 & 19 & 62 & 2.00 & 0.868 & 0.863 & 0.004 & 0.580 \\
\hline Oxy14 & 161 & 14 & 60 & 2.50 & 0.759 & $0.602 \ddagger$ & 0.118 & 0.379 \\
\hline Oxy15 & 162 & 6 & 60 & 2.50 & 0.162 & 0.173 & 0.037 & 0.013 \\
\hline Oxy17 & 162 & 6 & 60 & 2.50 & 0.695 & 0.685 & 0.001 & 0.275 \\
\hline Oxy19 & 159 & 3 & 60 & 2.00 & 0.551 & 0.560 & 0.009 & 0.151 \\
\hline Blm5 & 156 & 3 & 50 & 2.50 & 0.075 & 0.064 & 0.072 & 0.003 \\
\hline \multirow[t]{2}{*}{ Blm12 } & 149 & 7 & 60 & 2.50 & 0.479 & 0.483 & 0.008 & 0.119 \\
\hline & & & & & & \multicolumn{3}{|c|}{$\S$ Total exclusionary power $=0.933$} \\
\hline
\end{tabular}

*Number of adults genotyped at a locus.

†Probability of excluding a randomly chosen parent of an arbitrary offspring given only the offspring's genotype.

$\ddagger$ Significantly fewer heterozygotes observed than expected under Hardy-Weinberg equilibrium $(\mathrm{P}<0.05)$.

§Combined power of the 10 loci to exclude a candidate parent of an arbitrary offspring assuming both parents are unknown.

the population (Table 1). Eight of these loci (Oxy loci, Table 1) were developed specifically for ruddy ducks (Muñ oz-fuentes et al. 2005) and two (Blm loci, Table 1) for musk ducks (Biziura lobata) (Guay \& Mulder 2005).

To determine microsatellite genotypes for all individuals, we extracted genomic DNA from blood samples using standard phenol-chloroform methods after digestion with proteinase-K solution (Westneat 1990). To avoid fluorescently labelling individual primers, polymerase chain reactions (PCRs) were performed with three primers: a reverse primer, a forward primer with an M13 reverse or CAG tag added to the 5c-end, and a fluorescently labelled primer (M13 reverse or CAG tag labelled with one ABI PRISM ${ }^{\circledR}$ fluorescent tag: $6 F A M^{\mathrm{TM}}$, NED ${ }^{\mathrm{TM}}, \mathrm{VIC}^{\circledR}$, or $\mathrm{PET}^{\circledR}$ ), following Muñ oz-fuentes et al. (2005). For all Oxy primers, we amplified genomic DNA from each individual in 10 1L PCR reactions containing: $25 \mathrm{ng}$ of genomic DNA, 2-2.5 mM $\mathrm{MgCl}_{2}$ (see Table 1), $0.05 \mathbf{l}_{\mathrm{M}}$ of tag-labelled forward primer, $0.5 \mathbf{I}_{\mathrm{M}}$ of reverse primer, $0.45 \mathbf{I}_{\mathrm{M}}$ fluorescently labelled primer (M13 reverse or CAG tag), $0.15 \mathrm{~mm}$ of each dNTP, two units of Taq polymerase and 1x PCR buffer (PROMEGA). PCR conditions were $94^{\circ} \mathrm{C}$ for $6 \mathrm{~min}$, followed by 35 cycles of denaturation at $94{ }^{\circ} \mathrm{C}$ for $40 \mathrm{~s}$, annealing at optimal temperature (see Table 1) for $20 \mathrm{~s}$ and extension at $72{ }^{\circ} \mathrm{C}$ for $30 \mathrm{~s}$, followed by a final extension at $72{ }^{\circ} \mathrm{C}$ for $10 \mathrm{~min}$. For Blm primers, we modified forward primer sequences reported by Guay \& Mulder (2005) by adding an M13 reverse tag to the 5t-end. PCR reactions for Blm primers contained similar concentrations of reagents as above with the exception that primer concentrations were $0.33 \mathbf{l}_{\mathrm{M}}$ of tag-labelled forward primer, $0.34 \mathbf{l}_{\mathbf{M}}$ of reverse primer and $0.33 \mathbf{l}_{\mathbf{M}}$ fluorescently labelled primer. PCR conditions were $94{ }^{\circ} \mathrm{C}$ for $3 \mathrm{~min}$, followed by 30 cycles of denaturation at $94{ }^{\circ} \mathrm{C}$ for $1 \mathrm{~min}$, annealing at optimal temperature (Table 1) for $1 \mathrm{~min}$, extension at $72{ }^{\circ} \mathrm{C}$ for $45 \mathrm{~s}$, then a final extension at $72{ }^{\circ} \mathrm{C}$ for $5 \mathrm{~min}$. PCR products were visualized on an Applied Biosystems ABI 3730 automated capillary sequencer, and analyzed using GeneMapper 3.5 (Applied Biosystems).

For each locus, we calculated observed and expected heterozygosities, the frequency of null alleles and the probability of exclusion using CERVUS 3.0.3 (Kalinowski et al. 2007). We ran diagnostic tests on microsatellite loci including tests for deviations from HardyWeinberg and linkage disequilibrium using GENEPOP on the web (Raymond \& Rousset 1995), and for possible scoring errors due to allelic dropout or stuttering using the program MICRO-CHECKER (Van Oosterhout et al. 2004). We also used sequential Bonferroni correction to test loci for significant deviations from Hardy-Weinberg expectations (Rice 1989).

We assigned allele sizes for each individual at each locus, analyzed allelic mismatches between nesting females and offspring in their nests (i.e, the nesting female and the duckling in her nest shared no alleles at a specific locus), and assessed maternity using the software package CERVUS 3.0.3 (Kalinowski et al. 2007), which uses a maximum-likelihood approach to identify parents. However, because parentage can be difficult to assess genetically when neither parent is known, we also developed a set of conservative maternity assignment rules (see Results). In this study, we use these 
assignment rules and compare our results with the output from CERVUS.

\section{Statistical analyses}

After molecular identification of parasitic offspring, we used chi-square analysis to test for differences in parasitism frequencies across years, prior to pooling our estimates of parasitism. In addition, after assigning parasitic offspring to their mothers, we conducted statistical analyses to test for the influence of various factors on CBP behaviour. Prior to statistical analysis, we checked all data for normality, and we used nonparametric tests where appropriate.

Logistic regression was used to test if predation frequency on wetlands predicted the incidence of parasitism, and year was included as an additional effect in the model. For analyses of female condition, we calculated an index of physical condition controlled for female size. We used principle components analysis of multiple morphological measurements (tarsus, wing chord, bill length and width) to obtain a linear measure of size, where PC1 accounted for $43 \%$ of the overall variation among morphological measurements. We then ran an ordinary least squares regression analysis of log body mass on PC1 values, and used the residuals from the regression analysis as a measure of condition (the condition index). Although the use of ordinary least squares regression to evaluate condition is controversial (Green 2001), Schulte-Hostedde et al. (2005) refuted criticisms and demonstrated ordinary least squares regression is currently the most appropriate method to evaluate condition using morphological measurements. We used ANOva to test the differences in condition due to variation in female egg-laying behaviour (parasites vs. nonparasites), and included year and year by egglaying behaviour interaction term in the model.

To test for differences in the number of eggs laid by parasites and nonparasites, we used ANOva to examine variation in the total number of eggs laid (including parasitic eggs for parasites) between female types and also within clutch size (eggs in individual nests, parasitic eggs excluded) between parasites and nonparasites. Both models also included year.

We used logistic regression to test whether nest density influences the opportunity to lay eggs parasitically. Then, we used a two-tailed t-test for matched pairs to compare the distance from a nesting parasite's nearest active neighbour and the distance to the nest where she laid a parasitic egg. For this test, our sample size was $\mathrm{n}=39$, due to four copy errors in field data (i.e. missing GPS coordinates of locations).

Finally, we tested the hypothesis that nesting synchrony influences the opportunity to lay eggs parasiti- cally by examining whether nesting females lay parasitic eggs in host nests of similar nesting stage. For this purpose, we generated 100 host-parasite pairs by pairing a randomly chosen host with a nesting parasite (random pairs) and compared these with observed hostparasite pairs. Specifically, we calculated the dif- ference in number of days between the first laid egg in the parasitic female's own nest and the first laid egg in the host female's nest for random and observed pairs. We used ANOVA to test if the difference in time between egg laying for observed host-parasite pairs differed across years. Then, we used a two-tailed t-test to test if the difference in time between egg laying for random pairs (i.e. the expected time between egg laying if host choice is random) was different than that for observed host-parasite pairs within each year.

\section{Results}

Protein fingerprint identification of parasitic ducklings

Using four different gel types, we scored 57 variable protein bands. Among these bands, 16 were correlated (i.e. showed identical occurrence with at least one other band) with other bands, and were omitted from the analysis. Of the remaining 41 variable bands, the mean number per individual was $12.8 \pm 2.41$ (mean \pm SD), and the mean band frequency was $0.312 \pm 0.258$. Based on protein-banding patterns (parasitic eggs differed from host eggs by two or more bands), we identified 20 parasitic eggs out of the 126 eggs analyzed $[16 \% \pm 6$ ( $\pm 95 \%$ CI, assuming a binomial distribution)], and these occurred in 9 of 20 nests analyzed [45\% $\pm 22( \pm 95 \%$ CI)].

\section{Microsatellite identification of parasitic ducklings}

All 10 microsatellite loci were polymorphic (Table 1). We found no evidence of linkage disequilibrium across locus pairs after applying Bonferroni's sequential correction. Only one locus, Oxy14, showed a significant deviation from Hardy-Weinberg expectations; thus we did not identify parasitic offspring or assign maternity due to mismatches at this locus alone. Across all loci, we detected no cases of scoring errors due to allelic dropout or to stutter. Our combined probability that an arbitrarily chosen adult would not match the duckling at all 10 loci was 0.993 when both parents were unknown (Table 1).

To determine the number of locus mismatches expected for comparisons between unrelated individuals (i.e. the case for parasitic offspring compared to the nesting female), we generated a simulation data set of random female-offspring comparisons. We randomly 


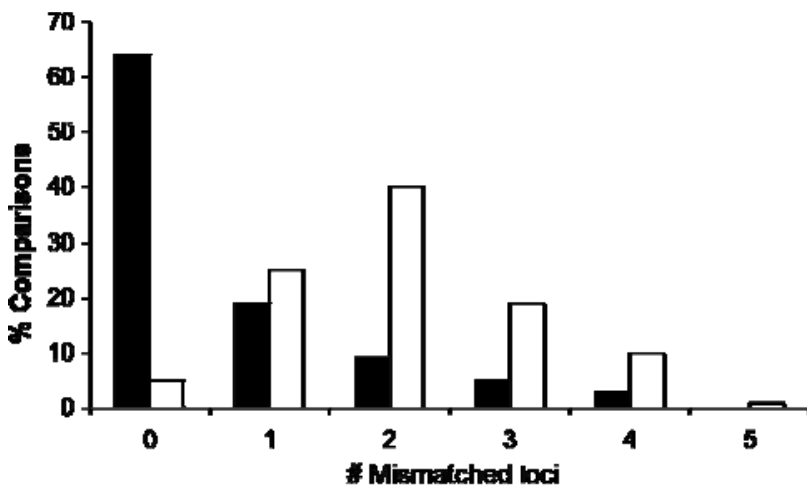

Fig. 2 Distribution of number of locus mismatches for comparisons between (1) nesting females and offspring in the nest (dark bars, $\mathrm{n}=525$ comparisons between females and the ducklings in their nests), and (2) randomly chosen females and offspring (white bars, $\mathrm{n}=100$ simulated pairs).

selected 100 offspring ( $£ 2$ per nest) and 100 females. We paired them randomly with the exception that ducklings were not paired to their nesting female (i.e. social parent). Then we contrasted the distribution of locus mismatches for the simulation data set (comparisons of unrelated individuals) with the distribution of nesting female/offspring mismatches observed in the population (Fig. 2). Comparison of these distributions indicated that unrelated pairings rarely resulted in zero locus mismatches, whereas zero mismatches were common between observed nesting females and offspring in their nests. Thus, cases with zero locus mismatches are indicative of biological parent-offspring relationships ( $n=334$ cases). Similarly, the simulation indicated unrelated pairings often had two or more locus mismatches (70 of 100 cases), whereas these were relatively rare in nesting female-offspring comparisons and most likely represented parasitic offspring ( $n=84$ cases). Cases of a single mismatch were prevalent in both distributions. In some cases, the single mismatch between a nesting female and a duckling in her nest were consistent with the presence of a null allele (i.e. parent-offspring mismatch where individuals appear homozygous for a locus, due to a nonamplifying allele); in these cases, we accepted the female as the biological mother of the duckling ( $n=18$ of 98 cases of single mismatches). All other cases of a single mismatch between the nesting female and a duckling were considered ambiguous, and we could not accurately discriminate parasitic ducklings from biological parent/offspring matches.

To obtain further resolution for these remaining ambiguous cases ( $\mathrm{n}=80$ single locus mismatches not attributed to a null allele), we examined distributions of likelihood scores (LODs) calculated by the program CERVUS for both biological parent/offspring comparisons and our simulation data set of unrelated pairs (Fig. 3). The two likelihood distributions overlapped

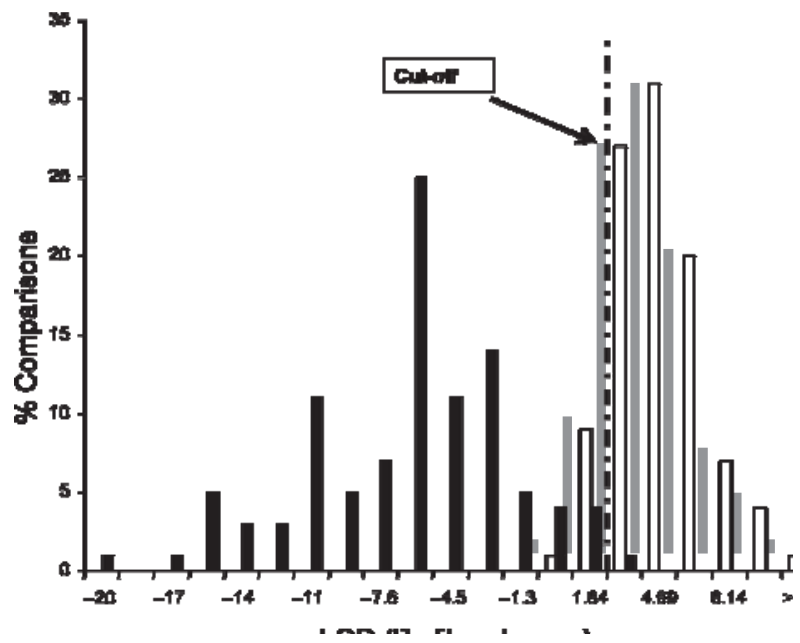

Fig. 3 Distribution of likelihood (LOD) scores for comparisons of biological parent/offspring (gray bars) and random female /offspring (black bars). LOD scores for nesting female/offspring comparisons with single mismatches were used to discriminate between host and parasitic ducklings. The dashed line indicates the lowest LOD score allowable for single mismatch cases where offspring in a nest were assigned to the nesting female. (Cut-off is $2 \mathrm{SD}$ from the mean LOD score for random parent/offspring comparisons).

from 0.14 to 1.87 (Fig. 3); we determined that adult offspring comparisons must have a LOD score greater than 1.87 (2 SD above the mean LOD for unrelated comparisons), to represent a biological parent/offspring relationship. Using this criterion, we distinguished parasitic ducklings from biological offspring for an additional 69 of 80 ambiguous cases (three biological offspring and 66 parasitic young); 11 cases remained ambiguous and were excluded from further analysis.

In total, microsatellite analyses detected 150 parasitic offspring of 505 offspring analyzed (ambiguous cases excluded; Table 2). The frequency of parasitic offspring differed significantly across years $\left(v^{2}=13.37\right.$, d.f. $=2$,

Table 2 Ducklings separated into two major maternity assignment categories (i.e. host ducklings and parasitic ducklings), and two subcategories describing maternity assignment among parasitic ducklings

\begin{tabular}{|c|c|c|c|c|}
\hline \multirow{2}{*}{$\begin{array}{l}\text { Maternity assignment } \\
\text { category }\end{array}$} & \multicolumn{3}{|l|}{ Year } & \multirow{2}{*}{$\begin{array}{l}\text { All } \\
\text { years }\end{array}$} \\
\hline & 2003 & 2004 & 2005 & \\
\hline $\begin{array}{l}\text { Host ducklings } \\
\text { (matched nesting female) }\end{array}$ & 58 & 128 & 169 & 355 \\
\hline $\begin{array}{l}\text { Parasitic ducklings } \\
\text { (did not match nesting female) }\end{array}$ & 29 & 73 & 48 & 150 \\
\hline Matched another female & 12 & 49 & 31 & 92 \\
\hline Matched no female & 17 & 24 & 17 & 58 \\
\hline
\end{tabular}

$\mathrm{n}=505$ total ducklings analyzed. Values are listed as number of ducklings. 
$\mathrm{P}=0.001$ ), with 2005 having proportionally fewer parasitic ducklings than the other 2 years. However, there was no significant difference in the percent of nests with parasitic eggs across years $\left(\mathrm{v}^{2}=5.139\right.$, d.f. $=2$, $\mathrm{P}=0.077)$, where 55 of 80 nests $[69 \% \pm 10( \pm 95 \% \mathrm{CI})]$ contained parasitic offspring.

For 18 offspring from five nests for which we had both egg albumen and blood, the two molecular techniques appeared to be equally successful in detecting parasitic eggs. In 17 cases, both albumen protein fingerprint and microsatellite egg identification agreed (identifying 14 eggs from nesting females and 3 parasitic eggs). In just one case, an egg identified as parasitic by protein fingerprinting was not detected as such using our stringent microsatellite criterion. In this case, CERVUS identified the nesting female as an unlikely candidate (low LOD score), but we assigned the duckling to the nesting female because the nesting female and the duckling had zero locus mismatches.

We found no significant difference in the number of parasitic nests detected by each technique (chi-square with conservative correction for small sample sizes; Fowler et al. 1998; $\mathrm{v}^{2}=2.474$, d.f. $=1, \mathrm{P}=0.116$ ). Thus, we pooled the two molecular data sets across years and found $67 \% \pm 9( \pm 95 \%$ CI $)$ of nests contained parasitic offspring (64 of 95 nests analyzed).

\section{Maternity assignment}

Using our parentage criteria, we assigned maternity to a total of 447 offspring of 505 analyzed (11 ambiguous cases excluded): 355 offspring were assigned to the nesting female incubating the clutch, and 92 of 150 parasitic offspring were assigned to other females. CERVUS agreed with assignments of females to offspring $81 \%$ of the time ( $n=365$ of 447 offspring assigned). Disagreement occurred because CERVUS did not assign nesting females to offspring in their nests 83 out of 355 cases, when the nesting female/offspring comparison had zero locus mismatches or a single mismatch explained by the presence of a null allele. In these cases, CERVUS assigned 19\% (16 of 83) of offspring to another female with high confidence, $71 \%$ (59 of 83) with low confidence and $10 \%$ were not assigned to any other female (8 of 83). In addition, we assigned parasitic females to 14 parasitic offspring when CERVUS did not assign with high confidence, because the candidate fit our other assignment criteria above.

\section{Parasitism as a conditional tactic}

Maternity assignment revealed that $50 \% \pm 9( \pm 95 \%$ CI $)$ of females in the population (56 of 112 females analyzed) laid eggs parasitically. On average, parasitic females laid $1.67 \pm 0.81$ parasitic eggs (mean \pm SD) in $1.55 \pm 0.66$ different nests. Of the females sampled, 86 nested on the study site, and of these $43[50 \% \pm 11$ ( $\pm 95 \%$ CI $)$ ] also laid eggs parasitically. We did not find nests for 13 females that laid eggs parasitically, but at least some of these females probably nested off the study site (see below). Similarly, nesting females for which we did not identify any parasitic young may have laid parasitic eggs in unsampled nests off the main study site. Thus, we found that $77 \% \pm 11( \pm 95 \%$ $\mathrm{CI})$ of identified parasites were females with nests of their own (43 of 56 parasitic females identified), and this is probably a minimum estimate for the proportion of females that lay parasitic eggs in addition to nesting on their own.

We found no evidence that female ruddy ducks lay parasitic eggs in response to nest loss, as nesting females laid parasitic eggs prior to, during and after initiating their own clutch (Fig. 4). Moreover, in all cases in which a nest was lost $(n=7)$, the female laid the parasitic egg prior to nest loss. Finally, a regression model that included both year and the frequency of nests depredated on a wetland revealed that these variables were not related to the incidence of parasitism on a wetland (logistic regression: $\mathrm{v}^{2}=0.076$, d.f. $=1, \mathrm{P}=0.783$ ).

Female condition varied significantly between years (ANOvA: $\mathrm{F}_{5,87}=46.37, \mathrm{n}=92, \mathrm{P}<0.0001$ ). However, the likelihood of laying parasitic eggs was not influenced by female condition (ANOva: $\mathrm{F}_{5,87}=0.001, \mathrm{n}=92$, $\mathrm{P}=0.970$ ), as females that laid parasitic eggs did not differ in physical condition from nonparasitic females. There was no effect of the interaction term, year by egg-laying behaviour (ANOvA: $\mathrm{F}_{5,87}=0.760, \mathrm{n}=92$, $\mathrm{P}=0.471)$.

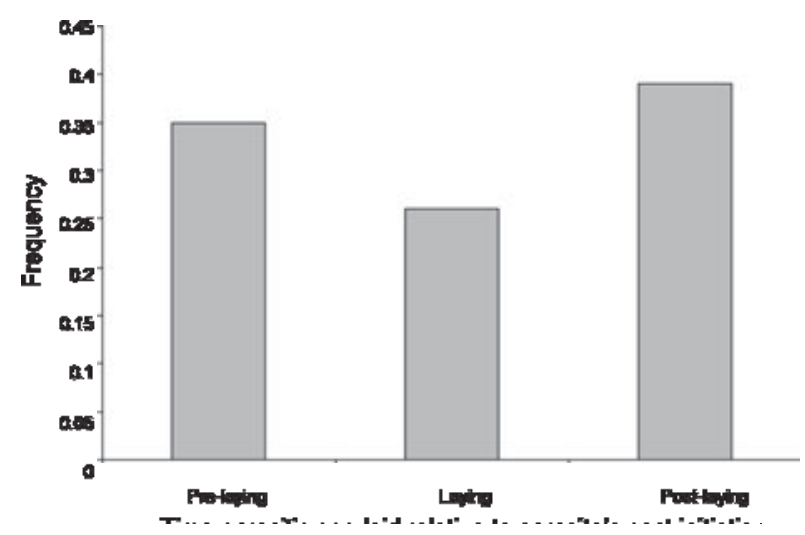

Fig. 4 Estimated time when a parasitic egg was laid relative to the parasite's nest initiation ( $\mathrm{n}=66$ females), $39 \%$ of females laid eggs after completing their own clutch (post-laying); however, in all cases where a nest was lost, the parasitic egg was laid prior to nest loss. Females also laid parasitic eggs pre-laying and during laying eggs in their own nests (35\% and 26\%, respectively). 
Average within-nest clutch size did not differ between parasitic and nonparasitic nesting females $[5.11 \pm 1.76$ (mean $\pm \mathrm{SD}$ ) vs. $5.39 \pm 1.19$ eggs, (ANova: $\left.\mathrm{F}_{5,31}=0.978, \mathrm{n}=36, \mathrm{P}=0.471\right)$ ], indicating that parasitic females are not merely redistributing the same number of eggs across multiple nests. Year was not a significant effect in the model (ANOvA: $\mathrm{F}_{5,31}=9.352, \mathrm{n}=36$, $\mathrm{P}=0.005)$. Accordingly, nesting females appeared to increase their reproductive output through opportunistic parasitism, as parasitic females produced significantly more eggs than nonparasitic females [6.79 \pm 1.90 (mean $\pm \mathrm{SD}$ ) vs. $5.39 \pm 1.19$ eggs, (ANova: $\mathrm{F}_{5,31}=9.352$, $\mathrm{n}=36, \mathrm{P}=0.005)]$. There was no year effect on the total number of eggs produced by females (ANova: $\left.\mathrm{F}_{5,31}=0.814, \mathrm{n}=36, \mathrm{P}=0.452\right)$.

What ecological factors influence the likelihood of opportunistic CBP?

We found no evidence that nest density influenced brood parasitism: logistic regression revealed the probability that a nest was parasitized, was not significantly related to the number of nests on a wetland or by year $\left(\mathrm{v}^{2}=3.213\right.$, d.f. $\left.=3, \mathrm{P}=0.360\right)$. We also tested whether nesting parasites $(n=39)$ were more likely to parasitize their nearest active neighbour; however, only $8 \% \pm 8$ $( \pm 95 \% \mathrm{CI})$ of females parasitized their nearest neighbour. Another $10 \% \pm 10$ ( $\pm 95 \% \mathrm{CI})$ of females laid eggs parasitically in nests less than $70 \mathrm{~m}$ from their nearest neighbour, and $82 \% \pm 12( \pm 95 \% \mathrm{CI})$ laid eggs parasitically in nests over $200 \mathrm{~m}$ beyond their nearest neighbour. On average, the nests of parasitic females were seven times further away from the nests they parasitized $(1680.89 \pm 1359.82 \mathrm{~m}$, mean $\pm \mathrm{SD})$ than they were from their nearest neighbours $(237.30 \pm 176.40 \mathrm{~m}$; twotailed t-test for paired data: $\mathrm{T}=$ ) 8.356, d.f. $=38$, $\mathrm{P}<0.0001$ ). Thus, the lack of an effect of nest density on parasitism was probably because parasitic females laid eggs in nests very distant from their own nests (e.g. Fig. 5), and were generally unlikely to parasitize their nearest neighbours.

A female might be more likely to parasitize host females with nests in synchrony with her own nest (i.e. when egg laying of the nesting parasitic female overlapped that of the female she parasitized). To estimate the degree of nesting synchrony between host-parasite pairs, we calculated the observed difference in days, when birds laid eggs in their own nests ( $n=63$ hostparasite pairs). The average number of days between egg laying for observed host-parasite pairs was $8.43 \pm 5.79$ (mean \pm SD) days, with no significant difference between years (ANOvA: $F_{2,60}=2.130, n=63$, $\mathrm{P}=0.128$ ). Next, we compared the difference in days between egg laying for these 63 host-parasite pairs with

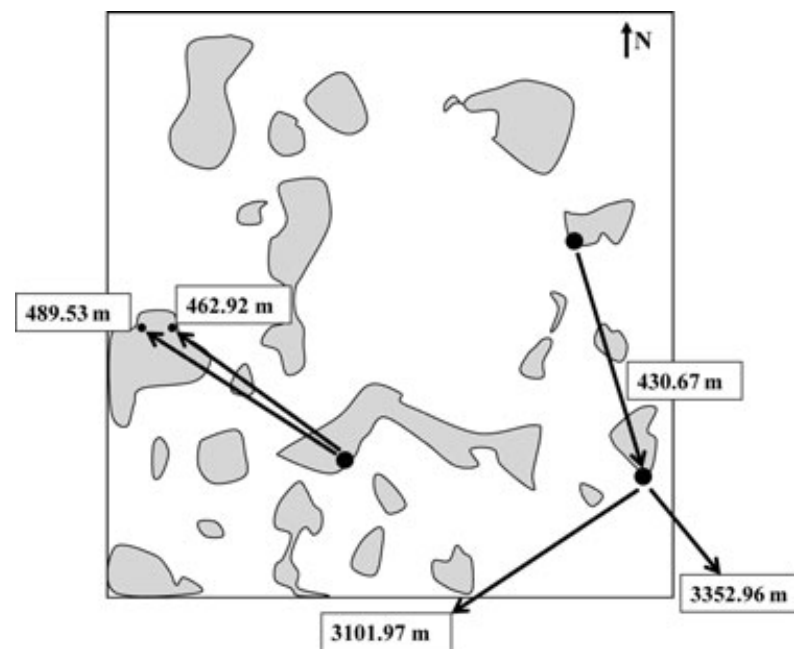

Fig. 5 Map of one quarter square mile of the study site, indicating the nests of three nesting females (large black circles) that also laid eggs parasitically. Wetlands are shaded gray. Arrows identify the location of nests those females parasitized, with distance (in metres) from parasite's nest to the nests parasitized indicated in boxes.

that for randomly selected pairs of females (mean \pm SD, $9.97 \pm 7.39$ days between initiation of laying at each nest). We found no significant difference in the average number of days between egg laying for observed hostparasite pairs and random female pairs for both 2003 (two-tailed t-test: $\mathrm{T}=0.938$, d.f. $=28, \mathrm{P}=0.356$ ) and 2005 (two-tailed t-test: $\mathrm{T}=0.694$, d.f. $=55, \mathrm{P}=0.491$ ). However, in 2004, observed host-parasite pairs were separated by $5.17 \pm 1.45$ (mean difference \pm SE) fewer days than female pairs in the random population (twotailed t-test: $\mathrm{T}=$ ) 3.563, d.f. $=73.14, \quad \mathrm{P}<0.001$ ), and were more synchronous than expected by chance, but this did not hold in the other 2 years.

\section{Discussion}

Identification of parasitic females and young

This is among the first studies to identify parasitic offspring and the females producing them in a wild population using molecular markers alone (see also Jaatinen et al. 2009), and to demonstrate that protein fingerprinting and microsatellites yield similar estimates of the frequency of CBP (see also Anderholm et al. 2009). Protein fingerprinting is useful for identifying parasitic offspring and for sampling eggs at a very early stage of incubation, reducing problems of small sample size caused by factors such as nest predation. However, it is less useful for identifying parasitic females because fingerprint pattern of eggs laid by one female may be identical to that of other females (Waldeck \& Andersson 2006; Anderholm et al. 2009), and must somehow be 
matched to the females who produced them (e.g. by behavioural observations; Andersson \& Åhlund 2000; Andersson \& Waldeck 2007; Anderholm et al. 2009). In contrast, microsatellites are powerful for assigning maternity to parasitic eggs, although a large number of loci are needed for adequate resolution when behavioural observations are difficult to obtain. We found microsatellites to be consistent with protein fingerprinting in identifying parasitic young, and we were able to match $61 \%$ of the parasitic offspring to their biological mothers. Our microsatellite analysis yielded one false negative, probably because we used only 10 microsatellites and our decision rules were somewhat conservative. We recommend that future studies use 10 or more highly polymorphic loci if at all possible.

Conspecific brood parasitism in ruddy ducks

Conspecific brood parasitism was common in this population of ruddy ducks, with $67 \%$ of nests parasitized by conspecifics. These estimates are similar to those obtained for other over-water nesting waterfowl (e.g. Sorenson 1991).

A general model (i.e. reproductive decisions model, Sorenson 1991) relating conditional female reproductive tactics to energy reserves provides two contexts in which CBP occurs. For each context, there are multiple hypotheses that could explain CBP, and our results allow us to exclude several of these for ruddy ducks. First, parasitism is clearly not a specialist or a conditional tactic employed by non-nesting females lacking sufficient energy reserves for independent nesting; most parasites in this population (77\% of 56 parasitic females identified) nested on their own in addition to laying parasitic eggs. Moreover, although we found no nests for the remaining parasitic females, at least some very likely had nests off the study site, given ruddy duck females often lay parasitic eggs relatively far from their own nesting site (Fig. 5). Females who produced parasitic eggs did not differ in condition from females who did not and nesting parasites were not females who had lost their nests and lacked reserves to re-nest (e.g., Jackson 1993).

Our results differ from those of studies examining female reproductive tactics in most other waterfowl species that show high levels of CBP (but see Åhlund \& Andersson 2001). In previous studies, parasitic females are often non-nesting females (but see Jaatinen et al. 2009) who are younger and/or in poor physiological condition compared with nonparasitic nesting females (e.g. Sayler 1985; Eadie 1989; Sorenson 1991, 1993; Lyon 1993a). Instead, CBP in ruddy ducks is consistent with a conditional reproductive tactic where parasitic eggs are laid opportunistically by nesting females. Nesting parasites probably incur increased fecundity (i.e. on average nesting parasites laid an additional egg compared with females who only nested), perhaps possible only by parasitism (i.e. females may be limited by clutch size in their own nest).

Overall, our results are consistent with Sorenson's (1991) reproductive decision model as modified to fit the reproductive biology of ruddy ducks (Fig. 1). Although we did not directly estimate costs of egg laying and nesting in this study, other studies provide support for these costs in ruddy ducks (e.g. Tome 1987; Alisauskas \& Ankney 1994). For ruddy ducks, the additional costs of nesting are probably minimal relative to the extreme cost of egg laying. Accordingly, reproductive effort required for egg laying and nesting are probably high, yet approximately equivalent. As such, females with insufficient energy reserves likely would not breed at all, whereas those with energy reserves sufficient to produce eggs would also be able to nest independently. Another study of ruddy ducks found a large proportion of nonbreeding females (20\% of 50 females, Siegfried 1976), possibly because these were females in poor condition. Female ruddy ducks also nest relatively later in the season than most other waterfowl (Brua 1998), and rarely re-nest (Tome 1987). These observations suggest that female ruddy ducks who are not ready to breed early in the season, will probably forgo breeding altogether, and nonnesting parasites should be rare.

\section{Ecological factors affecting the probability of opportunistic parasitism}

Nest density did not appear to enhance the occurrence of parasitism in ruddy duck nests in this species, as it does in some other species (Brown 1984; Sayler 1992; Møller 1998). This is probably because ruddy duck females rarely lay parasitic eggs in nests of nearest neighbours, and lay eggs parasitically in nests relatively far from their own. This is surprising given ruddy ducks are the least mobile of all North American waterfowl (Evans et al. 1952) and are rarely seen flying during the breeding season (Siegfried 1972; Brua 2001). Nonetheless, our results suggest that females are capable of travelling relatively long distances, even during egg laying when females are heaviest.

Most nesting parasites laid eggs in nests synchronous with their own, perhaps because of the generally high level of nesting synchrony in our population, although synchrony was significantly higher than that of randomly chosen female pairs in only one of 3 years. Moreover, female ruddy ducks may use other criteria in addition to nest synchrony to select hosts, such as host quality or relatedness among individuals (e.g. Andersson \& Åhlund 2000; Nielsen et al. 2006; Andersson \& 
Waldeck 2007). Further investigation of host/parasite relationships and analysis of costs and benefits associated with parasitic egg laying is required to reveal underlying mechanisms of CBP in ruddy ducks.

In summary, we have shown that CBP is common in ruddy ducks, a species where egg laying appears to be unusually costly (Alisauskas \& Ankney 1994). Most breeding females use a dual reproductive tactic where they nest and also lay parasitic eggs opportunistically, and, in this way, ruddy ducks differ from most other brood parasitic waterfowl studied to date.

\section{Acknowledgements}

We thank many field assistants for data collection and Malte Andersson for allowing L. Reichart to conduct protein fingerprint analyses at the University of Gothenburg. We thank Malte Andersson, John Eadie, Kim Jaatinen, Bruce Lyon, Nicole Odell, Hubert Schwabl, Paul Verrell and an anonymous reviewer for valuable comments on the manuscript. This study was supported by grants from Delta Waterfowl awarded to L. Reichart, from the National Science Foundation Doctoral Dissertation Enhancement Program (OISE-0532104) awarded to L. Reichart and M. Webster, and from the Ministry of Education of Spain Postdoctoral Fellowship program and the European Union Marie Curie Fellowship program awarded to V. Muñ oz-Fuentes.

\section{References}

Åhlund M, Andersson M (2001) Brood parasitism - female ducks can double their reproduction. Nature, 414, 600-601.

Alisauskas RT, Ankney CD (1992) The cost of egg laying and its relation to nutrient reserves in waterfowl. In: Ecology and Management of Breeding Waterfowl (eds Batt BDJ, Afton AD, Anderson MG et al.), pp. 30-61. University of Minnesota Press, Minneapolis.

Alisauskas RJ, Ankney CD (1994) Costs and rates of egg formation in ruddy ducks. Condor, 96, 11-18.

Anderholm S, Marshall RC, van der Jeugd HP, Waldeck P, Larsson K, Andersson M (2009) Nest parasitism in the barnacle goose: evidence from protein fingerprinting and microsatellites. Animal Behaviour, 78, 167-174.

Andersson M, Åhlund M (2000) Host-parasite relatedness shown by protein fingerprinting in a brood parasitic bird. Proceedings of the National Academy of Sciences USA, 97, 13188-13193.

Andersson M, Åhlund M (2001) Protein fingerprinting: a new technique reveals extensive conspecific brood parasitism. Ecology, 82, 1433-1442.

Andersson M, Eriksson MOG (1982) Nest parasitism in goldeneyes Bucephala clangula: some evolutionary aspects. American Naturalist, 120, 1-16.

Andersson M, Waldeck P (2007) Host-parasite kinship in a female-philopatric bird population: evidence from relatedness trend analysis. Molecular Ecology, 16, 2797-2806.

Arnold KE, Owens IPF (2002) Extra-pair paternity and egg dumping in birds: life history, parental care and the risk of retaliation. Proceedings of the Royal Society of London Series BBiological Sciences, 269, 1263-1269.
Bellrose FC (1980) Ducks, Geese, and Swans of the North America. Stackpole, Harrisburg, PA.

Blums P, Davis JB, Stephens SE, Mednis A, Richardson DM (1999) Evaluation of a plasticine-filled leg band for day-old ducklings. Journal of Wildlife Management, 63, 656-663.

Breault AM, Cheng KM (1989) Use of submerged mist nets to capture diving birds. Journal of Field Ornithology, 61, 328330.

Brockman HJ (1993) Parasitizing conspecifics: comparisons between Hymenoptera and birds. Trends in Ecology and Evolution, 8, 2-4.

Brown CR (1984) Laying eggs in a neighbor's nest: benefit and cost of colonial living in swallows. Science, 224, 518-519.

Brua RB (1998) Factors affecting reproductive success of male and female ruddy ducks (Oxyura Jamaicensis) in Southwestern Manitoba, Canada. PhD Dissertation, University of Dayton, Dayton.

Brua RB (2001) Ruddy duck (Oxyura jamaicensis). In: The Birds of North America, No. 696 (eds Poole A, Gill F). The Birds of North America, Inc., Phildelphia, PA.

Brua RB, Machin KL (2000) Determining and testing the accuracy of incubation state of ruddy duck eggs by floatation. Wildfowl, 51, 181-189.

Carbonell M(1983) Comparative studies of stiff-tailed ducks (Tribe Oxyurini, Anatidae). PhD Dissertation, University College, Cardiff, Wales.

Eadie JM (1989) Alternative reproductive tactics in a precocial bird: the ecology and evolution of brood parasitism in goldeneyes. $\mathrm{PhD}$ Dissertation, University of British Columbia, Vancouver, BC.

Eadie JM (1991) Constraint and opportunity in the evolution of brood parasitism in waterfowl. Acta Congr Int Ornithol, 20, 1031-1040.

Eadie JM, Fryxell JM (1992) Density dependence, frequency dependence, and alternative nesting strategies in goldeneyes. American Naturalist, 140, 621-641.

Evans CD, Hawkins AS, Marshall WH (1952) Movements of waterfowl in Manitoba. United States Fish and Wildlife Service Special Scientific Report, Wildlife No. 16. US Fish and Wildlife Service, Washington, DC, USA.

Feare CJ (1991) Intraspecific nest parasitism in Starlings Sturnus vulgaris: effects of disturbance on laying females. Ibis, 133, 75-79.

Fowler J, Cohen L, Jarvis P (1998) Practical Statistics for Field Biology. John Wiley \& Sons, Chichester, UK.

Gray BJ (1980) Reproduction, energetics, and social structure of the ruddy duck. PhD Disseration, University of California Davis, Davis, CA.

Green AT (2001) Mass/length residuals: measures of body condition or generators of spurious results? Ecology, 82, 1473-1483.

Guay PJ, Mulder RA (2005) Isolation and characterization of microsatellite markers in musk duck (Biziura lobata : Aves), and their application to other waterfowl species. Molecular Ecology Notes, 5, 249-252.

Haramis GM, Alliston WG, Richmond ME (1983) Dump nesting in the wood duck traced by tetracycline. Auk, 100, 729-730.

Harris RN, Hames WW, Knight IT, Carreno CA, Vess TJ (1995) An experimental analysis of joint nesting in the Salamander Hemidactylium-scutatum (Caudata, Plethodontidae) - the effects of population density. Animal Behaviour, 50, 1309-1316. 
Jaatinen K, Jaari S, O’Hara RB, Ost M, Merila J (2009) Relatedness and spatial proximity as determinants of hostparasite interactions in the brood parasitic Barrow's goldeneye (Bucephala islandica). Molecular Ecology, 18, 27132721.

Jackson WM (1992) Estimating conspecific nest parasitism in the northern masked weaver based on within-female variability in egg appearance. Auk, 109, 435-443.

Jackson WM (1993) Causes of conspecific nest parasitism in the northern masked weaver. Behavioral Ecology and Sociobiology, 32, 119-126.

Joyner DE (1975) Nest parasitism and brood-related behaviour of the ruddy duck (Oxyura Jamaicensis Rubida). PhD Dissertation, University of Nebraska, Lincoln, NE.

Joyner DE (1983) Parasitic egg laying in redheads and ruddy ducks in Utah: incidence and success. Auk, 100, 717-725.

Kalinowski ST, Taper ML, Marshall TC (2007) Revising how the computer program CERVUS accommodates genotyping error increases success in paternity assignment. Molecular Ecology, 16, 1099-1106.

Lahti DC, Lahti AR (2002) How precise is egg discrimination in weaverbirds? Animal Behaviour, 63, 1135-1142.

Lyon BE (1993a) Conspecific brood parasitism as a flexible reproductive tactic in American coots. Animal Behaviour, 46, 911-928.

Lyon BE (1993b) Tactics of parasitic American coots: host choice and the pattern of egg dispersion among host nests. Behavioral Ecology and Sociobiology, 33, 87-100.

Lyon BE (1998) Optimal clutch size and conspecific brood parasitism. Nature, 392, 380-383.

Lyon BE, Eadie JM (2008) Conspecific brood parasitism in birds: a life-history perspective. Annual Review of Ecology Evolution and Systematics, 39, 343-363.

McRae SB, Burke T (1996) Intraspecific brood parasitism in the moorhen: parentage and parasite-host relationships determined by DNA fingerprinting. Behavioral Ecology and Sociobiology, 38, 115-129.

Møller AP (1998) Density-dependent intraspecific nest parasitism and anti-parasite behavior in the barn swallow Hirundo rustica. In: Parasitic Birds and Their Hosts: Studies in Coevolution (eds Rothstein SI, Robinson SK), pp. 396-406. Oxford University Press, Oxford.

Muñ oz-fuentes V, Gyllenstrand N, Negro JJ, Green AJ, Vila C (2005) Microsatellite markers for two stifftail ducks: the white-headed duck, Oxyura leucocephala, and the ruddy duck, O. jamaicensis. Molecular Ecology Notes, 5, 263-265.

Nielsen CR, Semel B, Sherman PW, Westneat DF, Parker PG (2006) Host-parasite relatedness in wood ducks: patterns of kinship and parasite success. Behavioral Ecology, 17, 491496.

Pelayo JT, Clark RG (2000) Effects of a nasal marker on behavior of breeding female ruddy ducks. Journal of Field Ornithology, 71, 484-492.

Pelayo JT, Clark RG (2002) Variation in size, composition, and quality of Ruddy Duck eggs and ducklings. Condor, 104, 457-462.

Pelayo JT, Clark RG (2003) Consequences of egg size for offspring survival: a cross-fostering experiment in Ruddy ducks (Oxyura jamaicensis). Auk, 120, 384-393.

Pinxten R, Eens M, Verheyen RF (1991) Conspecific nest parasitism in the european starling. Ardea, 79, 15-30.
Raymond M, Rousset F (1995) GENEPOP (VERSION-1.2) population-genetics software for exact tests and ecumenicism. Journal of Heredity, 86, 248-249.

Rice WR (1989) Analysing tables of statistical tests. Evolution, 43, 223-225.

Richardson DS, Jury FL, Blaakmeer K, Komdeur J, Burke T (2001) Parentage assignment and extra-group paternity in a cooperative breeder: the Seychelles warbler (Acrocephalus sechellensis). Molecular Ecology, 10, 2263-2273.

Righetti PG (1990) Immobilized pH Gradients. Theory and methodology Elsevier, Amsterdam.

Sayler RD (1985) Brood parasitism and reproduction of canvasbacks and redheads on the delta marsh. PhD Dissertation, University of North Dakota, Grand Forks, ND.

Sayler RD (1992) Brood parasitism in waterfowl. In: Ecology and Management of Breeding Waterfow (eds Batt BDJ, Afton AD, Anderson MG et al.), pp. 290-322. University of Minnesota Press, Minneapolis.

Schulte-Hostedde AI, Zinner B, Millar JS, Hickling GJ. (2005) Restitution of mass-size residuals: validating body condition indices. Ecology, 86, 155-163.

Semel B, Sherman PW (2001) Intraspecific parasitism and nestsite competition in wood ducks. Animal Behaviour, 61, 787803.

Siegfried WR (1972) Ruddy ducks colliding with wires. Wilson Bulletin, 84, 486-487.

Siegfried WR (1976) Breeding biology and parasitism in the Ruddy Duck. Wilson Bulletin, 88, 566-574.

Sommerville AJ (1985) Advantages to late breeding in ruddy ducks. MS Thesis, University of British Columbia, Vancouver, BC.

Sorenson MD (1991) The functional significance of parasitic egg laying and typical nesting in redhead ducks: an analysis of individual behavior. Animal Behaviour, 42, 771-796.

Sorenson MD (1993) Parasitic egg laying in canvasbacks: frequency, success and individual behavior. Auk, 110, 57-69.

Tallamy DW (2005) Egg dumping in insects. Annual Review of Entomology, 50, 347-370.

Tome MW (1987) An observation of renesting by a ruddy duck, Oxyura jamaicensis. Canadian Field-Naturalist, 101, 153154.

Trivers RL (1972) Parental investment and sexual selection. In: Sexual Selection and the Descent of Man: 1871-1971 (ed.Campbell BG), pp. 136-179. Aldine Press, Chicago, IL.

Van Oosterhout C, Hutchinson WF, Wills DPM, Shipley P (2004) MICRO-CHECKER: software for identifying and correcting genotyping errors in microsatellite data. Molecular Ecology Notes, 4, 535-538.

Waldeck P, Andersson M (2006) Brood parasitism and nest take-over in common eiders. Ethology, 112, 616-624.

Weller MW (1957) An automatic nest-trap for waterfowl. Journal of Wildlife Management, 21, 456-458.

Westneat DF (1990) Genetic parentage in the indigo bunting: a study using DNA fingerprinting. Behavioral Ecology and Sociobiology, 27, 67-76.

White PS, Densmore LD, III (1992) Mitochondrial DNA Isolation. In: Molecular Genetic Analysis of Populations (ed. Hoelzel AR), pp. 29-58. Oxford University Press, Oxford.

Wisenden BD (1999) Alloparental care in fishes. Reviews in Fish Biology and Fisheries, 9, 45-70.

Yom-Tov Y (1980) Intraspecific nest parasitism in birds. Biological Reviews, 55, 93-108. 
Yom-Tov Y (2001) An updated list and some comments on the occurrence of intraspecific nest parasitism in birds. Ibis, 143, 133-143.

L.M.R. combines fieldwork and laboratory techniques to examine animal reproductive behaviour and waterfowl ecology. S. A. is interested in the study of broad parasitism and kinship in waterfowl. V.M.-F. is interested in applying genetic techniques to answer questions about the ecology and evolution of species. M.S.W. combines genetic analyses with field experimentation to examine the evolution of sexual signals and reproductive strategies in birds, particularly Australian fairywrens and North American warblers. 